\title{
The Changes of Gene Expression and Protein Level of Stretch-Activated Chloride Channel in Atrial Myocardium of Dogs with Atrial Fibrillation
}

\author{
Hongwei Shi, MD, ${ }^{1,2}$ Zhenming Jiang, MD,${ }^{2}$ Teng Wang, MD,${ }^{3}$ Yuting Chen, $M D,{ }^{3}$ Desheng Hu, MD, ${ }^{1}$ \\ Guang Han, MD, ${ }^{1}$ Feng Cao, MD ${ }^{3,4,5}$ \\ ${ }^{1}$ Department of Radiation Oncology, Hubei Cancer Hospital, Wuhan, China; \\ ${ }^{2}$ Department of Oncology, Renmin Hospital of Wuhan University, Wuhan, China; \\ ${ }^{3}$ Department of Cardiology, Renmin Hospital of Wuhan University, Wuhan, China; \\ ${ }^{4}$ Cardiovascular Research Institute, Wuhan University, Wuhan, China; 5Hubei Key Laboratory of Cardiology, Wuhan, China
}

\section{ABSTRACT}

Introduction: $\mathrm{ICl}$,stretch have been reported to be involved in the development of atrial fibrillation, so we observed the changes of transcription and translation levels of $\mathrm{ICl}$,stretch in isolated atrial myocardium of heart failure canine models.

Material and methods: In the control group $(\mathrm{N}=10)$, five dogs were untreated and the other five received sham operation, while dogs in the heart failure group $(\mathrm{N}=10)$ were implanted with cardiac pacemakers and underwent right ventricular pacing to induce heart failure. Cardiac structure and function were evaluated. The gene expression and protein level of ICl,stretch in the left atrial appendage were detected.

Results: The left atrial diameter, right atrial dimension, left ventricular diastolic dimension, and right ventricular diastolic dimension were significantly larger in the heart failure group $(P<0.05)$. In contrast, the ejection fraction and the left ventricular shorten fraction were higher in the control group $(P<0.05)$. Both the mRNA and protein expression levels of $\mathrm{ICl}$,stretch in atrial myocardium of the heart failure group were significantly higher compared with the control group.

Conclusion: $\mathrm{ICl}$,stretch might play an important role in the vulnerability to atrial fibrillation in dilated atria with heart failure and could be a potential therapeutic target for atrial fibrillation.

\section{INTRODUCTION}

Cardiovascular disease is commonly encountered in the adult population and has large impacts on morbidity and mortality [Slostad 2020]. Chloride channel, a functionally and structurally diverse group of anion-selective channels, recently has been studied extensively [Jentsch 2018]. Stretch-activated

Received fune 16, 2021; accepted fuly 8, 2021.

Correspondence: Feng Cao, Department of Cardiology, Renmin Hospital of Wuban University; Cardiovascular Research Institute, Wuban University; Hubei Key Laboratory of Cardiology, Wuban, Hubei Province, China, Telephone 136-2728-7313, Fax 136-2728-7313 (e-mail:lmcf72@126.com). chloride channels (ICl,stretch) are a major group of chloride channels [Sadoshima 1997], which are now known to be widely distributed among various tissues, including aortic endothelial cells, brain, heart, taste buds, testes, and ovaries [Jentsch 1999]. Studies have shown that ICl,stretch channels are involved in the development of cardiomyotrophy, heart failure, and cardiac arrhythmia [Inoue 2006; Gupta 2016]. However, whether the atrium level of ICl,stretch changes after heart failure and atrial fibrillation still remains unclear.

The hemodynamic perturbation, which is conventionally known as the cause of congestive heart failure and cellular hypertrophy, places myocytes under mechanical stress and thus leads to complex cellular remodeling and activation of multiple intracellular signaling systems [Arnaout 2003; Duan 2011]. Using the perforated-patch voltage clamp method, it was found that an inwardly rectifying, Gd3+-sensitive cation current was normally detected only after osmotic cell swelling [Clemo 1997] and became persistently activated under isosmotic conditions in ventricular myocytes isolated from animals with tachycardia-induced congestive heart failure [Clemo 1998]. Moreover, the inhibition of ICl,stretch resulted in significant volume changes in normal rabbit myocytes [Seol 2008], as well as in normal and congestive heart failure canine myocytes [Danetz 2000]. Therefore, we hypothesize that $\mathrm{ICl}$,stretch may play a role in the electrical activity of cardiac atrium cells and rhythm activity of sinus node cells. This study aimed to observe the atrium level of ICl,stretch during heart failure and investigate the potential effects of ICl,stretch in the development of atrial fibrillation associated with heart failure.

\section{MATERIALS AND METHODS}

Experimental animals: Twenty adult beagles, either male or female, weighing $15.4 \pm 2.5 \mathrm{~kg}$ randomly were divided into two groups: 10 canines in the heart failure group and 10 in the control group (among them, 5 canines received a sham operation). All the animals were housed in the same feeding and living conditions, with access to food and water ad libitum. The experimental protocols and procedures of the present study were approved by the institutional animal review board of Wuhan University, approval number is SYXK (Hubei) 
2004-0027. The study adhered to all applicable institutional guidelines for the care and use of animals.

Establishment of the study models: The pacemaker was introduced into the pacing-overdrive dog under general anesthesia $(30 \mathrm{mg} / \mathrm{kg}$ pentobarbital sodium, maintained with inhaled halothane). A bipolar electrode was inserted through a small incision in the right internal jugular vein, and the tip was positioned in the right ventricular apex under fluoroscopic guidance. The pacemaker (Shanghai Fudan Science \& Technology Co. Ltd., Shanghai, China) was placed in a cervical subcutaneous pocket, with a stimulation rate of 30 stimuli/ min. The canines received antibiotics after surgery. All of the animals recovered after 3 weeks without pacing. The canines in the heart failure group received antibiotics and recovered 3 days after implantation.

Heart failure was induced as previously described [Clemo 1998]. The canines underwent ventricular rapid pacing in VOO mode (240 beats/min, $0.2 \mathrm{~ms}$ pulse width with voltages of $5 \mathrm{~V}$ ) for 3 weeks. After 3 weeks, the heart was exposed in a pericardial cradle. Multielectrode catheters were secured to allow recording at the left atrial appendage and the left atrium. Similar electrode catheters were attached to the right atrial appendage and the right atrium. The difference between the longest and shortest S1-S2 interval during atrial fibrillation induction was defined as the window of vulnerability. After that, an S1-S1 programmed stimulation method (120-ms, 100-ms, and 75 -ms cycle length for $5 \mathrm{~s}$, respectively) was adopted to induce atrial fibrillation. Atrial fibrillation was defined as irregular atrial rates faster than 500 beats $/ \mathrm{min}$.

Echocardiography: Three weeks after the operation, echocardiography was performed using GE Vivid7 Ultrasound System (GE Healthcare, Chicago, IL, USA) to measure the left atrial diameter (LAD), right atrial dimension (RAD), left ventricular diastolic dimension (LVDD), right ventricular diastolic dimension (RVDD), ejection fraction (EF), and left ventricular shorten fraction (FS).

Reverse transcription-polymerase chain reaction (RT-PCR): Total RNA from heart tissue was extracted using TRIzol $^{\circledR}$ Reagent (Invitrogen, Carlsbad, CA, USA). $50 \mathrm{mg}$ of heart tissue was homogenized before $1.0 \mathrm{ml}$ of TRIizol Reagent was added. The sample was incubated at room temperature for 15 mins and then a 0.2 fold-volume of chloroform was added. The sample was centrifuged for 15 mins with $12,000 \times \mathrm{g}$ at $4^{\circ} \mathrm{C}$ after vortexing. A 0.5 fold-volume of isopropyl alcohol was added and then the sample was mixed and incubated at $-20^{\circ} \mathrm{C}$ for 15 mins. The sample tube was centrifuged at $4^{\circ} \mathrm{C}$ with $12,000 \mathrm{xg}$ for 10 mins. The supernatant was collected, and the RNA was precipitated with $1.0 \mathrm{ml} 75 \%$ ethanol by vortexing and then centrifugated at $4^{\circ} \mathrm{C}$ with $7,500 \times \mathrm{g}$ for 5 mins. After discarding the supernatant, the RNA pellet was air dried. $\mathrm{RNase}$-free sterile $\mathrm{H}_{2} \mathrm{O}$ was used to completely dissolve the RNA. RT-PCR was employed to measure the expression of mRNA. TURBO DNA-free ${ }^{\mathrm{TM}}$ DNase (Ambion, Foster City, CA, USA) was utilized to eliminate genomic DNA contamination in the RNA sample. An oligo $(\mathrm{dT})_{20}$ and SuperScript III Reverse Transcriptase (Invitrogen, Carlsbad, CA, USA) was used for cDNA synthesis. Subsequently, a 225 bp segment of $\mathrm{I}_{\mathrm{Cl} \text {,stretch }} \mathrm{cDNA}$ was PCR-amplified with a sense primer 5'-CATTGGCGTG TATTCAGC-3' and an antisense primer 5'-CATTCCGTCGAGGTCTCA-3'. The PCR was run for 35 cycles after an initial denaturing for 5 mins at $95^{\circ} \mathrm{C}$. Each PCR cycle was composed of $30 \mathrm{~s}$ of denaturing at $94^{\circ} \mathrm{C}, 30 \mathrm{~s}$ of annealing at $52^{\circ} \mathrm{C}$ and $30 \mathrm{~s}$ of primer extension at $72^{\circ} \mathrm{C}$. The PCR products were further extended at $72^{\circ} \mathrm{C}$ for 5 mins in the final stage and then stored at $4^{\circ} \mathrm{C}$. The DNA samples were examined through $1.5 \%$ agarose gel electrophoresis. An automatic gel imaging and analysis system was employed to scan the gel after ethidium bromide staining. The intensities of DNA bands were then scored before performing the semi-quantitative analysis.

Western blot: Three weeks after the operation, the left auricle of the heart was excised and flushed with saline before mincing into minute pieces. One milliliter of cold tissue lysis buffer was added before the tissue was homogenized. After centrifugation at $14,000 \mathrm{rpm}$ at $4^{\circ} \mathrm{C}$, the supernatant was mixed with $200 \mu \mathrm{l}$ of $0.01 \mathrm{M}$ Tris- $\mathrm{Cl}$ buffer ( $\mathrm{pH}$ 7.6). The sample was centrifuged at $14,000 \mathrm{rpm}$ at $4^{\circ} \mathrm{C}$ for 10 mins. Again, the supernatant was collected. Bradford method was employed to quantify the protein content before the sample was stored in a freezer at $-70^{\circ} \mathrm{C} .20 \mu \mathrm{g}$ of total protein samples were mixed with $5 \times$ SDS loading buffer, boiled for 3 mins and then loaded to a $10 \%$ SDS-polyacrylamide gel for electrophoresis. The samples were then transferred to a nitrocellulose membrane under constant electrical current of $350 \mathrm{~mA}$ for 1 h. The membrane was blocked with $5 \%$ non-fat milk in TBS buffer with $0.1 \%$ Tween-20 (TBST) for $1 \mathrm{~h}$ and then incubated overnight with $\mathrm{I}_{\mathrm{Cl} \text { stretch }}$ polyclonal antibody (ab28736, Abcam, USA) diluted at 1:500 in TBST containing 5\% nonfat milk at $4^{\circ} \mathrm{C}$. After washing 3 times with TBST, the membrane was then incubated with a goat anti-rabbit IgG antibody conjugated with HRP diluted at 1:2500 in TBST containing $5 \%$ non-fat milk for $1 \mathrm{~h}$. After washing with TBST, the membrane was finally incubated with enhanced chemiluminescent reagent for $1 \mathrm{~min}$ and exposed to a film. Subsequently, the protein band intensity on the film was quantified.

Data analysis: SPSS17.0 statistical software was used for data analysis. Data were expressed as mean \pm standard deviation (SD). Student $t$ test was used to examine the difference between the two groups. P value of less than 0.05 was considered statistically significant.

\section{RESULTS}

Structural and functional changes of the hearts: The results of the echocardiography are shown in Table 1 and Figure 1. (Table 1) (Figure 1) The heart failure group showed significantly larger LAD, RAD, LVDD, and RVDD $(P<0.05$, for all indices) compared with the control group. However, the heart failure group had a significantly lower EF and FS (both $P<0.05)$. These data indicate that the heart failure models were successfully established.

The left auricular tissue mRNA expression levels were $0.0362 \pm 0.0021$ and $0.0987 \pm 0.0042$ in the control group and in the heart failure group, respectively. (Figure 2) The $\mathrm{I}_{\mathrm{Cl} \text { stretch }}$ mRNA expression level was significantly higher in the heart 
Table 1. Results of echocardiography of canines in atrial fibrillation and control groups $( \pm s)$

\begin{tabular}{lcc}
\hline & Control group & Atrial fibrillation \\
\hline $\operatorname{LAD}(\mathrm{mm})$ & $18.5 \pm 2.0$ & $23.2 \pm 2.7^{*}$ \\
$\operatorname{RAD}(\mathrm{mm})$ & $14.1 \pm 1.7$ & $18.7 \pm 1.9^{*}$ \\
$\operatorname{LVDD}(\mathrm{mm})$ & $27.2 \pm 2.2$ & $36.9 \pm 2.8^{*}$ \\
$\operatorname{RVDD}(\mathrm{mm})$ & $12.6 \pm 1.5$ & $15.1 \pm 1.6^{*}$ \\
$\operatorname{LVEF}(\%)$ & $72.3 \pm 6.8$ & $48.9 \pm 5.9^{*}$ \\
FS $(\%)$ & $41.2 \pm 6.0$ & $25.4 \pm 8.2^{*}$ \\
\hline
\end{tabular}

*Compared with control group, $P<0.05$

failure group $(P<0.05)$. As shown in Figure 3, the $\mathrm{I}_{\mathrm{Cl}, \text { stretch }}$ protein level in the left auricular tissue of the heart failure group $(0.4715 \pm 0.087)$ was markedly higher than that of the control group $(0.1385 \pm 0.0078, P<0.05)$. (Figure 3 )

\section{DISCUSSION}

In this study, we aimed to observe the changes in $\mathrm{I}_{\mathrm{Cl}, \text { stretch }}$ gene expression and protein level in atrial myocardial tissue of atrial fibrillation canine models. Our results revealed that an enhanced expression of the $\mathrm{I}_{\mathrm{Cl} \text {,stretch }}$ gene at both mRNA and protein levels was observed during heart failure. $\mathrm{I}_{\mathrm{Cl} \text {,stretch }}$ channels are a group of anion channels located on the plasma membrane. Swelling-activated chloride channel $\left(\mathrm{I}_{\mathrm{Cl}, \text { swell }}\right)$ is observed in $>80 \%$ of human atrial and ventricular myocytes and rabbit ventricular myocytes as evaluated by the perforated patch method and canine ventricular myocytes swollen by hyperosmotic pipette solution [Baumgarten 2003; Seol 2008]. $\mathrm{I}_{\mathrm{Cl} \text {,swell }}$ is chronically activated under isosmotic conditions in ventricular myocytes isolated from a canine rapid pacing dilated cardiomyopathy model [Clemo 1998], and similar results are obtained in ventricular myocytes from rabbit aortic regurgitation, canine infarct and peri-infarct zone cells, and human atrial myocytes from patients with right atrial enlargement [Hagiwara 1992; Sato 1998; Bray 2018]. The most recent literature demonstrated that $I_{C{ }_{1} \text { stretch }}$ is involved in the activation of stretch-activated ion channels. When activated, they may enhance an early phase of repolarization during action potential or delay a late phase of repolarization. Therefore, $\mathrm{I}_{\mathrm{Cl}, \text { stretch }}$ is likely involved in the development of arrhythmia [Kamkin 2003].

It is generally accepted that mechanical burden has an important effect on the induction of arrhythmia. The electrical feedback to mechanical force is mainly controlled by stretch-activated ion channels, but their activation may cause the development of stretch-induced arrhythmia. Franz et al. discovered that $\mathrm{I}_{\mathrm{Cl} \text { stretch }}$ has the characteristic functions of stretch-activated ion channels [Franz 2003]. Their study in isolated rabbit hearts demonstrated that rapid increase in intra-atrium pressure induces atrial fibrillation [Bode 2001].

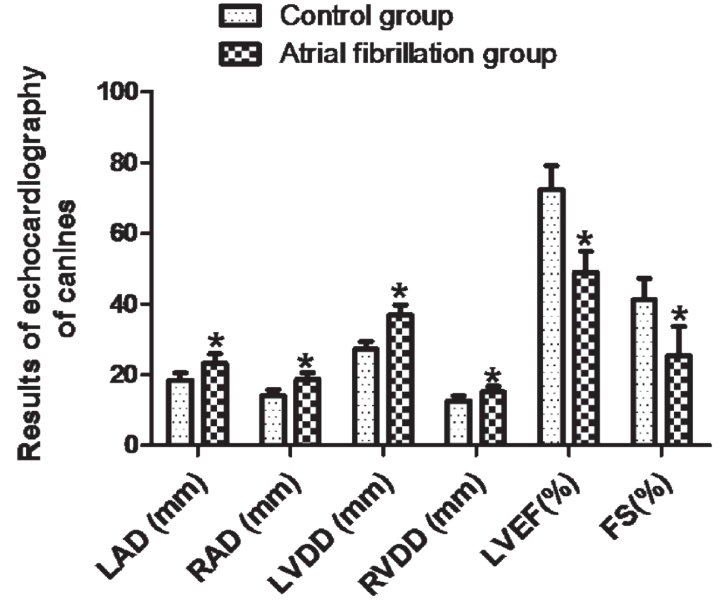

Figure 1. Results of echocardiography of canines in atrial fibrillation and control groups $\left({ }^{x} \pm s\right)$

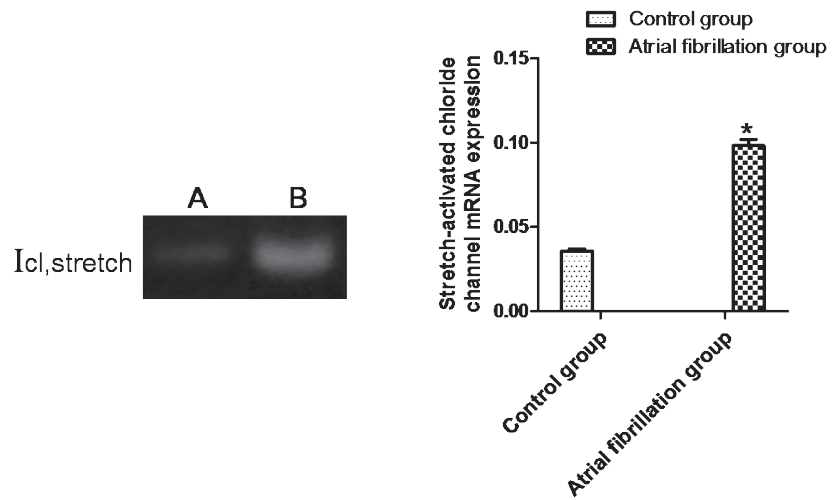

Figure 2. Expression of $\mathrm{ICl}$,stretch mRNA in atrial myocardia of canines obtained by RT-PCR. A: control group; B: atrial fibrillation group. For details, see experimental procedures.
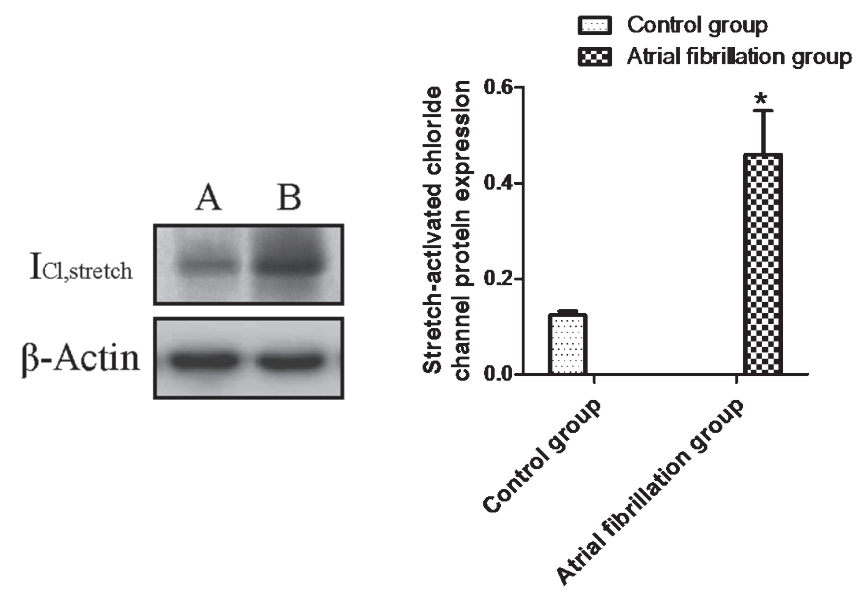

Figure 3. Expression of protein level of $\mathrm{ICl}$, stretch in atrial myocardia of canines by western blot. A: control group; $\mathrm{B}$ : atrial fibrillation group 
Research has found that stretching could modulate several ionic currents [Kamkin 2000]. In fact, prolongation of both the plasma membrane depolarization and the action potential is controlled by the currents of stretch-activated ion channels. Moreover, these currents have a tendency to cause arrhythmia [Kamkin 2000]. In hypertrophic ventricular myocardial cells, stretch-activated ion channels are more reactive compared with normal ventricular myocardial cells [Crozatier 1996]. It is postulated that $\mathrm{I}_{\mathrm{Cl}, \text { stretch }}$ may be involved in stretch-induced arrhythmia and that heart failure is likely to enhance the development of stretch-induced cardiac rhythmic disorders [Li 2000].

Heart failure is an essential risk factor for the development of atrial fibrillation [Rosamond 2008; Sridhar 2009]. During the disease progression of heart failure, the incidence rate of atrial fibrillation is as high as $10 \%$ to $35 \%$. Ionic redistribution is one of the important pathophysiologic characteristics of heart failure [ $\mathrm{Lu} 2017$ ], although the role $\mathrm{I}_{\mathrm{Cl}, \text { stretch }}$ and its clinical significance remain unclear. In the present study, we found that $\mathrm{I}_{\mathrm{Cl}, \text { stretch }}$ expression in atrial myocardial tissue at both mRNA and protein levels was markedly enhanced after heart failure. It is likely that $\mathrm{I}_{\mathrm{Cl} \text { sstretch }}$ participates in ion channel reconstruction and thus plays a role in the development of atrial fibrillation. More detailed mechanisms of action remain to be further investigated. Also, the relationship between atrial fibrillation after heart failure and $\mathrm{I}_{\mathrm{Cl}, \text { stretch }}$ is still unclear and should be further studied.

DCPIB has been shown to block anion channels and related currents [Suchyna 2000]. However, it did not affect potentialdependent $\mathrm{Ca}^{2}+$ and $\mathrm{K}+$ channels and was not cross-reactive to potential-dependent channels. Thus, DCPIB is a specific blocker for stretch-activated ion channels. DCPIB significantly reduced the occurrence of atrial fibrillation induced by stretching of the atrium [Bode 2001]. Since it has been proven that $\mathrm{I}_{\mathrm{Cl} \text { stretch }}$ is expressed in human atrial and ventricular tissues [Sato 1998], these results indicated that DCPIB could be a potential candidate for treating atrial fibrillation. Our study is ongoing to validate the rescue effect of DCPIB in our heart failure canine model.

\section{CONCLUSION}

$\mathrm{I}_{\mathrm{Cl} \text { stretch }}$ might play an important role in the vulnerability to atrial fibrillation in dilated atria with heart failure and could be a potential therapeutic target for atrial fibrillation.

\section{REFERENCES}

Arnaout MS and Alam SE. 2003. "Congestive heart failure: new paradigms and therapeutic targets." Le Journal médical libanais. The Lebanese medical journal. 51(3): 169.

Baumgarten CM and Clemo HF. 2003. "Swelling-activated chloride channels in cardiac physiology and pathophysiology." Progress in Biophysics \& Molecular Biology. 82(1): 25-42.

Bode F, Sachs F, and Franz MR. 2001. "Tarantula peptide inhibits atrial fibrillation." Nature. 409(6816): 35-36.
Bray F, Ferlay J, Soerjomataram I, Siegel RL, Torre LA, and Jemal A. 2018. "Global cancer statistics 2018: GLOBOCAN estimates of incidence and mortality worldwide for 36 cancers in 185 countries." CA: a cancer journal for clinicians. 68(6): 394-424.

Clemo HF and Baumgarten CM. 1997. "Swelling-activated Gd3+-sensitive cation current and cell volume regulation in rabbit ventricular myocytes." The Journal of General Physiology. 110(3): 297-312.

Clemo HF, Stambler BS, and Baumgarten CM. 1998. "Persistent Activation of a Swelling-Activated Cation Current in Ventricular Myocytes From Dogs With Tachycardia-Induced Congestive Heart Failure." Circulation Research. 83(2): 147-157.

Crozatier B. 1996. "Stretch-induced modifications of myocardial performance: from ventricular function to cellular and molecular mechanisms." Cardiovascular Research. 32(1): 25-37.

Danetz JS, Daviesb RD, Clemo HF, and Baumgarten CM. 2000. "Rabbit ventricular myocyte volume changes as a direct result of crystalloid cardioplegia in congestive heart failure induced by aortic regurgitation." The Journal of Thoracic and Cardiovascular Surgery. 119(4): 826-833.

Duan DD. 2011. "The ClC-3 chloride channels in cardiovascular disease." Acta Pharmacologica Sinica. 32(6): 675-684.

Franz MR and Bode F. 2003. "Mechano-electrical feedback underlying arrhythmias: the atrial fibrillation case." Progress in Biophysics \& Molecular Biology. 82: 163-174.

Gupta VM, P. S. P. 2016. "Studies on Chloride Channels and their Modulators." Current Topics in Medicinal Chemistry. 16(16): 1862-1876.

Hagiwara N, Masuda H, Shoda M, and Irisawa H. 1992. "Stretch-activated anion currents of rabbit cardiac myocytes." The Journal of Physiology. 456(1): 285-302.

Inoue R, Jensen LJ, Shi J, Morita H, Nishida M, Honda A, and Ito Y. 2006. "Transient Receptor Potential Channels in Cardiovascular Function and Disease." Circulation Research. 99(2): 119-131.

Jentsch TJ, Friedrich T, Schriever A, and Yamada H. 1999. "THE CLC CHLORIDE CHANNEL FAMILY." Pflügers Archiv: European Journal of Physiology. 437(6): 783-795.

Jentsch TJ and Pusch M. 2018. "CLC Chloride Channels and Transporters: Structure, Function, Physiology, and Disease." Physiological Reviews. 98(3): 1493-1590.

Kamkin A, Kiseleva I, and Isenberg G. 2000. "Stretch-activated currents in ventricular myocytes: amplitude and arrhythmogenic effects increase with hypertrophy." Cardiovascular Research. 48(3): 409-420.

Kamkin A, Kiseleva I, Wagner K, Bohm J, Theres H, Gunther J, and Scholz H. 2003. "Characterization of stretch-activated ion currents in isolated atrial myocytes from human hearts." Pflügers Archiv: European Journal of Physiology. 446(3): 339-346.

Li D, Melnyk P, Feng J, Wang Z, Petrecca K, Shrier A, and Nattel S. 2000. "Effects of Experimental Heart Failure on Atrial Cellular and Ionic Electrophysiology." Circulation. 101(22): 2631-2638.

Lu YY, Cheng CC, Tsai CF, Lin YK, Lee TI, Chen YC, Chen S, and Chen YJ. 2017. "Discrepant effects of heart failure on electrophysiological property in right ventricular outflow tract and left ventricular outflow tract cardiomyocytes." Clinical Science. 131(12): 1317-1327.

Rosamond W, Flegal KM, Furie KL, Go AS, Greenlund KJ, Haase N, Hailpern SM, Ho M, Howard VJ, and Kissela B. 2008. "Heart Disease and Stroke Statistics-2008 Update. A Report From the American Heart Association Statistics Committee and Stroke Statistics Subcommittee." Circulation. 117(4). 
Sadoshima J and Izumo S. 1997. "THE CELLULAR AND MOLECULAR RESPONSE OF CARDIAC MYOCYTES TO MECHANICAL STRESS." Annual Review of Physiology. 59(1): 551-571.

Sato R and Koumi S. 1998. "Characterization of the Stretch-activated Chloride Channel in Isolated Human Atrial Myocytes." The Journal of Membrane Biology. 163(1): 67-76.

Seol CA, Kim WT, Ha JM, Choe H, Jang YJ, Youm JB, Earm YE, and Leem CH. 2008. "Stretch-activated currents in cardiomyocytes isolated from rabbit pulmonary veins." Progress in Biophysics \& Molecular Biology. $97(2): 217-231$.

Slostad BD, Khalsa TK, Young KA, Guerra H, and Bhagra A. 2020. "A case-based approach to integrative medicine for cardiovascular disease prevention." Journal of Integrative Medicine. 18(2): 159-162.

Sridhar A, Nishijima Y, Terentyev D, Khan M, Terentyeva R, Hamlin RL, Nakayama T, Gyorke S, Cardounel AJ, and Carnes CA. 2009. "Chronic heart failure and the substrate for atrial fibrillation." Cardiovascular Research. 84(2): 227-236.

Suchyna TM, Johnson JH, Hamer K, Leykam JF, Gage DA, Clemo HF, Baumgarten CM, and Sachs F. 2000. "Identification of a Peptide Toxin from Grammostola spatulata Spider Venom That Blocks Cation-Selective Stretch-Activated Channels." The Journal of General Physiology. 115(5): 583-598. 